\title{
Risk of penile tumor development in Caucasian individuals is independent of the coding variant rs7208422 in the TMC8 (EVER2) gene
}

\author{
ROBERT STOEHR ${ }^{1,2}$, OLAF WENDLER ${ }^{2,3}$, JOHANNES GIEDL ${ }^{1,2}$, NADINE T. GAISA $^{4}$, \\ GEORG RICHTER $^{5}$, VALENTINA CAMPEAN ${ }^{6}$, MAXIMILIAN BURGER ${ }^{7}$, \\ BERND WULLICH $^{2,8}$, SIMONE BERTZ $^{1,2}$ and ARNDT HARTMANN ${ }^{1,2}$
}

\begin{abstract}
${ }^{1}$ Institute of Pathology, University Hospital Erlangen, Friedrich-Alexander-University Erlangen-Nürnberg; ${ }^{2}$ Comprehensive Cancer Center Erlangen-EMN (CCC ER-EMN); ${ }^{3}$ Department of Otorhinolaryngology-Head and Neck Surgery, University Hospital Erlangen, Friedrich-Alexander-University Erlangen-Nürnberg, D-91054 Erlangen;

${ }^{4}$ Institute of Pathology, RWTH Aachen University, D-52074 Aachen; ${ }^{5}$ Institute of Pathology, D-31785 Hameln; ${ }^{6}$ Institute of Pathology, D-91522 Ansbach; ${ }^{7}$ St. Josef Medical Centre, Department of Urology, University Regensburg, De-93053 Regensburg; ${ }^{8}$ Department of Urology, University Hospital Erlangen, Friedrich-Alexander-University Erlangen-Nürnberg, D-91054 Erlangen, Germany
\end{abstract}

Received July 7,2021; Accepted August 26, 2021

DOI: $10.3892 / \mathrm{mco} .2021 .2429$

\begin{abstract}
Genetic variation in the transmembrane channel-like (TMC)6/TMC8 region has been linked to $\beta$-type human papillomavirus (HPV) infection and squamous cell carcinoma (SCC) of the skin and the head and neck, $\alpha$-type HPV persistence and progression to cervical cancer. The functional variant rs7208422 of the TMC8 gene was suggested to have a high impact on susceptibility to $\beta$-papillomaviruses and their oncogenic potential and to also have an influence on $\alpha$-type HPV-related disease. The aim of the present study was to evaluate a possible influence of rs7208422 on penile cancer risk, a known $\alpha$-type HPV-related malignancy. Therefore, the distribution of rs7208422 was determined by direct Sanger sequencing of 104 Caucasian penile SCC cases and compared to data of 3,810 controls taken from the literature. HPV detection was performed by usage of GP5+/6+ primers and subtype-specific PCR. It was observed that the distribution of rs7208422 followed the Hardy-Weinberg equilibrium in both cases and controls. HPV DNA was detected in $39 \%$ of the penile SCC cases. Overall, there was no significant difference in the distribution of rs7208422 neither between cases and controls $(\mathrm{P}=0.726)$ nor between HPV-positive and
\end{abstract}

Correspondence to: Professor Robert Stoehr, Institute of Pathology, University Hospital Erlangen, Friedrich-AlexanderUniversity Erlangen-Nürnberg, Krankenhaus street 8-10, D-91054 Erlangen, Germany

E-mail: robert.stoehr@uk-erlangen.de

Key words: penile cancer, TCM8, rs7208422, sequencing, SNP, $\mathrm{HPV}$, squamous cell carcinoma -negative penile SCC cases $(\mathrm{P}=0.747)$. There was also no association between rs7208422 genotypes and age of disease onset $(\mathrm{P}=0.740)$. In conclusion, the present data argue against a significant impact of rs7208422 on the risk for the development of penile SCC in Caucasians. Even in combination with the HPV status, the SNP appears not to influence the risk of penile SCC in HPV-positive cases.

\section{Introduction}

Human papillomavirus (HPV) infection is a causal factor in numerous epithelial disorders (1). Infection with high-risk HPV (e.g. HPV16 or HPV18) is an important prerequisite for the development of several malignancies such as cervical, anal or head and neck cancer. Persistent infection with HPV is crucial but HPV alone is inadequate to induce carcinogenesis in most cases. Furthermore, additional endogenous or exogenous factors are required to unfold the tumorigenic potential of HPV (2). Although marked efforts were made to reveal the molecular mechanisms of viral integration and progression to cancer (3), the current understanding of genetic susceptibility to HPV infection and any resulting cancer risk is limited.

In recent years, two members of a novel gene family named transmembrane channel-like (TMC) were identified to have an important role in abnormal susceptibility to papillomaviruses, particularly to $\beta$-papillomaviruses. The function of the eight TMC family members still remains to be fully elucidated. Alterations in TMC6 and TMC8 were identified in patients with epidermodysplasia verruciformis (EV), a rare skin disease caused by $\beta$-papillomaviruses. EV is an autosomal recessive genodermatosis that is associated with an increased risk for skin cancer. TMC6 (also called EVER1) and its adjacent homolog TMC8 (also called EVER2) are both located on chromosome $17 q 25$. The screening of patients and families 
with EV revealed 12 different mutations (nonsense, frameshift and splice-site mutations) in TMC6 and TMC8. The functional roles of these two proteins were mainly investigated in keratinocytes. TMC6 and TMC8 interact with zinc (Zn) transporter $\mathrm{ZnT} 1$ and are associated with the transfer from $\mathrm{Zn}$ from the cytoplasm into the endoplasmatic reticulum and are therefore responsible for the regulation of the cellular $\mathrm{Zn}$ balance. The actual model suggests that mutations in TMC6 and TMC8 interrupt the interaction with $\mathrm{ZnT} 1$ in patients with EV. This leads to an increased cellular Zn concentration, increasing the activation of the AP-1 transcription factor, which is essential for the expression of the virus genome $(4,5)$. Besides mutations, three single nucleotide polymorphisms (SNP) have been described in the TMC6/TMC8 genes (6-8). In particular, the genotype status of rs7208422 (c.917A $>$ T, p.N306I) was suggested to be of high relevance in the susceptibility to EV. Homozygosity of the minor T-allele was detected in two sisters with EV and a very young (22 years of age) HIV-positive patient with EV (6,7). Subsequently, the role of rs7208422 in $\alpha$-HPV-associated cancer risk was also investigated in several malignancies. It was revealed that the SNP did not influence the risk for cervical cancer (9). For squamous cell carcinoma (SCC) of the head and neck, as well as for cutaneous SCC, conflicting results were obtained, as certain studies provided evidence for an influence of the SNP on disease risk, while others suggested no influence on the disease risk (10-13). For the additional TMC6/TMC8 SNPs, the results on the cervical cancer risk as reported by the first single case-control studies were also conflicting in a similar way to that described above $(14,15)$. These data underline a potential general impact of TMC6/TMC8 SNPs on HPV-related carcinogenesis that requires to be clarified in more detail.

Another $\alpha$-HPV-associated cancer is SCC of the penis (16). This malignancy is a rare but biologically aggressive disease. Particularly with the presence of metastasis, the disease has a poor prognosis (17). Although it is an infrequent tumor entity in the Western world, penile cancer accounts for $17 \%$ of all malignancies specific to males in developing countries $(18,19)$. Among several other risk factors (18), HPV infection was detectable in 30-40\% of all penile cancer cases analysed worldwide (20). For a long time, the molecular background of penile carcinogenesis was poorly understood, but with recent comprehensive genomic analyses, deeper insight into affected genes and pathways was gained (21). However, the exact mechanisms of non-HPV and HPV-related penile tumorigenesis have remained to be revealed. In addition, inherited risk factors for penile SCC have remained largely unexplored, making it difficult to identify individuals with high disease risk in general or in combination with an HPV infection. The potential susceptibility function of the TMC6/TMC8 genes described above, particularly the promising results of the influence of rs7208422 on HPV-related cancer risk, prompted us to investigate the role of this SNP in a large Caucasian cohort of penile cancer cases and compare the distribution of the genotypes with a control group of healthy individuals.

\section{Materials and methods}

Tissue specimens. Archival formalin-fixed paraffin-embedded (FFPE) tumor and non-tumorous tissue from 104 cases of penile SCC were used for the analysis. All tumors of the cohort were classified and staged according to the World Health Organization classification of penile tumors and the current American Joint Committee on Cancer/TNM-classification system $(22,23)$. The cases analyzed are part of a larger cohort described previously (24). The clinicopathological characteristics of the subset of cases used in the present study are presented in Tables I and II.

Microdissection of tissue and DNA isolation. Microdissection and isolation of genomic DNA from FFPE tissue were performed as described previously $(24,25)$. As a prerequisite, serial tissue sections (5 $\mu \mathrm{m}$ thickness) were dewaxed, rehydrated and stained with $0.1 \%$ methylene blue $(15 \mathrm{sec}$ at room temperature). Tumor and non-tumorous tissue (identified through matching with a marked H\&E-stained section reviewed by an experienced surgical pathologist) were isolated from the sections using a sterile cannula under microscopic control (inverted microscope). Subsequent DNA isolation was performed using the Blood DNA Preparation Kit (Maxwell $^{\circledR} 16$ System; Promega Corporation) according to the manufacturer's protocols.

Sequencing analysis of rs7208422. Genomic location of rs7208422 in exon 8 of the TMC8 gene was amplified by PCR (primers: Sense, 5'-CGCTTCCAGCTGATG CAG-3' and antisense, 5'-CACCTCCTTGTTGTCCTG-3'; obtained from Metabion. The PCR reaction mixture (total volume of $25 \mu \mathrm{l}$ ) contained $\sim 150 \mathrm{ng}$ DNA, $0.2 \mathrm{mM}$ dNTP (PromegaCorporation), $0.18 \mu \mathrm{M}$ primers and $0.0025 \mathrm{U} / \mu \mathrm{lGoTaq}$ (Promega Corporation). Following thermocycling conditions were used: initial denaturation for $3 \mathrm{~min}$ at $95^{\circ} \mathrm{C}, 45$ cycles of denaturation at $94^{\circ} \mathrm{C}$ for $1 \mathrm{~min}$, annealing at $56.7^{\circ} \mathrm{C}$ for $1 \mathrm{~min}$, elongation at $72^{\circ} \mathrm{C}$ for $1 \mathrm{~min}$ and final primer extension at $72^{\circ} \mathrm{C}$ for $10 \mathrm{~min}$. Prior to the analysis, gradient PCR was used for the optimization of the cycling conditions. The resulting PCR products (size, $153 \mathrm{bp}$ ) were purified (Qiagen Dye Ex 2.0 ${ }^{\mathrm{TM}}$ Spin Kit; Qiagen $\mathrm{GmbH}$ ) and sequenced with the PCR sense primer using a Big Dye Terminator v.1.1 Cycle Sequencing Kit and an ABI 3500 Genetic Analyzer (both from Applied Biosystems; Thermo Fisher Scientific, Inc.) according to manufacturer's protocol.

HPV DNA detection in penile tumor tissue. HPV DNA was amplified via PCR using GP5+/6+ primers as described previously (26). For HPV-positive cases, subsequent subclassification of HPV species was performed using type-specific primers as described previously $(27,28)$.

Statistical analysis. For Hardy-Weinberg equilibrium testing public software available at https://wpcalc.com/en/equilibrium-hardy-weinberg/ was used. $\chi^{2}$ statistics (2-sided exact significance) were used to evaluate case-control differences in the distribution of genotypes and to analyze associations between genotypes and HPV status. To determine the distribution of the risk allele vs. the non-risk allele, Fisher's exact test (2-sided exact significance) was used. Statistical analysis was performed using SPSS version 13.0 (SPSS, Inc.). $\mathrm{P}<0.05$ was considered to indicate a statistically significant difference. 
Table I. Clinicopathological characteristics of the analysed cases $(n=104)$.

\begin{tabular}{lc}
\hline Item & Value \\
\hline Age (years) & \\
Median (range) & 68 (39-93) \\
Mean \pm SD & $67.6 \pm 12$ \\
Tumor stage & \\
pTis & 6 \\
pTa & 1 \\
pT1a & 42 \\
pT1b & 8 \\
pT2 & 31 \\
pT3 & 11 \\
pT4 & 1 \\
Unknown & 4 \\
Tumor grade & \\
1 & 21 \\
2 & 35 \\
3 & 38 \\
Unknown & 4 \\
HPV status & \\
Positive & \\
Negative & 39 \\
Unknown & 61 \\
\hline Values are expressed as n unless otherwise specified. SD, standard \\
deviation; HPV, human papillomavirus. \\
\hline
\end{tabular}

\section{Results}

HPV analysis. In the first step, the percentage of HPV-positive and -negative cases in the present cohort was determined. The determination of the HPV status gave interpretable results in $100 / 104(96 \%)$ of cases analysed. A total of four cases did not exhibit positivity for the internal positive control and were therefore excluded from the HPV analysis due to inadequate DNA quality. HPV DNA was detectable in 39/100 (39\%) penile SCC samples with $21 / 39(54 \%)$ cases of the subtypes HPV16 or HPV18 and 5/39 (13\%) cases of the subtypes HPV13, $-31,-33,-45,-52$ or -58 . In $13 / 39(33 \%)$ cases, only the positive signal from the HPV consensus PCR was detected but the subtype-specific PCR gave no signal. In these cases, it was not possible to determine the exact HPV subtype.

rs7208422 genotyping analysis. In the second step, the allelic frequencies of rs7208422 within the present cohort were investigated. Sequencing analysis of rs7208422 in exon 8 of the TMC8 gene (presented in Fig. 1) was performed on tumor and non-tumorous tissue from each penile SCC case. From $31 / 104(30 \%)$ cases, a result was only obtained either from the tumor or from the non-tumorous tissue. As no genotype change between the tissue samples of any one patient was observed within the remaining cohort, the results from all cases were used for the following analyses. It was not possible to analyse an
Table II. Histological subtypes of penile SCC according to HPV status.

\begin{tabular}{lcc}
\hline Histological subtype & HPV-negative & HPV-positive \\
\hline Usual type & 33 & 7 \\
Verrucous & 11 & - \\
Basaloid & 3 & 13 \\
Warty-basaloid & 3 & 7 \\
Pseudohyperplastic & 6 & 1 \\
Warty & 1 & 2 \\
Lymphoepithelioma-like & - & 2 \\
Clear cell & 1 & 1 \\
Sarcomatoid & 1 & 1 \\
Carcinoma cuniculatum & 1 & - \\
Unknown (n=2) & $/$ & $/$ \\
\hline
\end{tabular}

Values are expressed as $n$ unless otherwise specified. HPV, human papillomavirus.

Table III. Genotype distribution of rs7208422 in controls and cases.

\begin{tabular}{lcrr}
\hline Variant & $\begin{array}{c}\text { Cases } \\
(\mathrm{n}=104)\end{array}$ & $\begin{array}{c}\text { Controls } \\
(\mathrm{n}=3,810)\end{array}$ & P-value \\
\hline TMC8 p.N306 & $25(24.0)$ & $965(25.3)$ & 0.726 \\
TMC8 p.N306/I306 & $50(48.0)$ & $1,917(50.3)$ & \\
TMC8 p.I306 & $29(28.0)$ & $928(24.4)$ & \\
\hline
\end{tabular}

Values are expressed as n (\%). TMC, transmembrane channel-like.

internal healthy control group for comparison within the present study. Therefore, published genotype data (from peripheral blood) of rs7208422 from Caucasian control groups of several published case-control studies were used (9-12,29,30). After merging these studies, genotype data from 3,810 control cases were available. The used cases of the control groups were not matched to our cases (e.g. in terms of age). It was determined that the distribution of rs7208422 followed the Hardy-Weinberg equilibrium in both cases $(\mathrm{P}=0.143)$ and controls $(\mathrm{P}=0.156)$. Comparing the genotype distribution of rs7208422 between cases and controls, no significant difference $(\mathrm{P}=0.726)$ between the two cohorts was obtained (Table III). To test the influence of age of disease onset, the genotype distribution was compared between cases whose age was lower or equal to the median age of the penile SCC cohort (median age, 68 years) and cases older than the median age (Table IV). No significant difference was obtained $(\mathrm{P}=0.904)$. Next, the influence of rs7208422 genotypes on disease risk was analysed according to the HPV status of the penile SCC cases (Fig. 2, Table V). No significant difference in genotype distribution was obtained between HPV-positive and HPV-negative cases $(\mathrm{P}=0.747)$. In addition, neither the use of the dominant $(\mathrm{P}=0.477)$ nor the recessive $(\mathrm{P}=0.820)$ model resulted in the determination of a significant difference. 

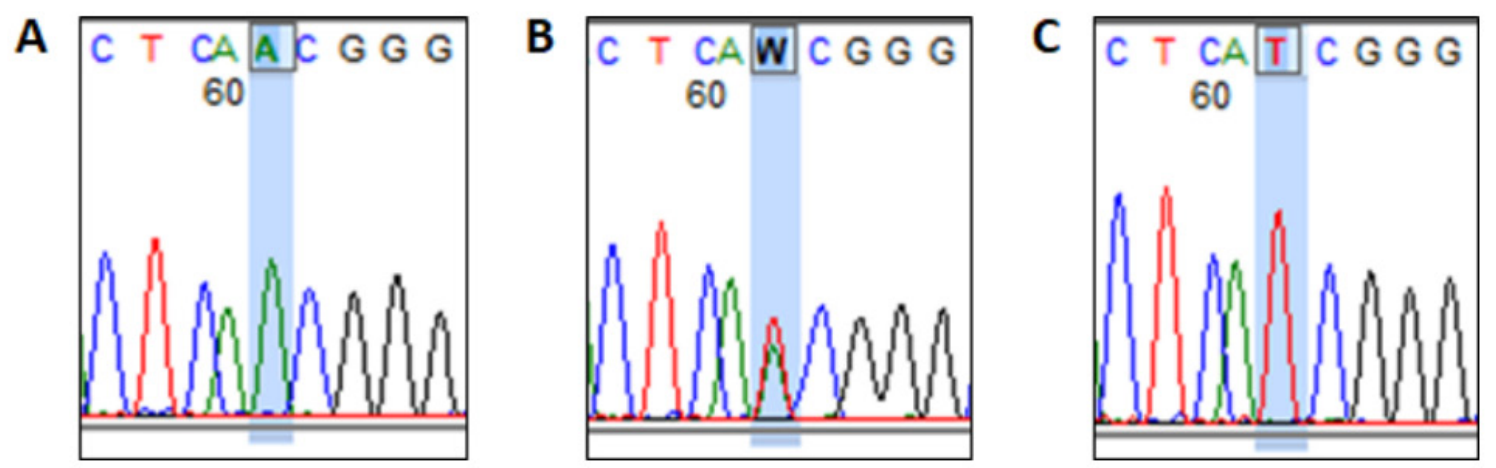

Figure 1. Representative examples of rs7208422 sequencing indicating (A) homozygous wild-type alleles p.N306 (c.917A), (B) heterozygous p.N306/I306 alleles (c.917A/T) and (C) homozygous variant alleles p.I306 (c.917T).

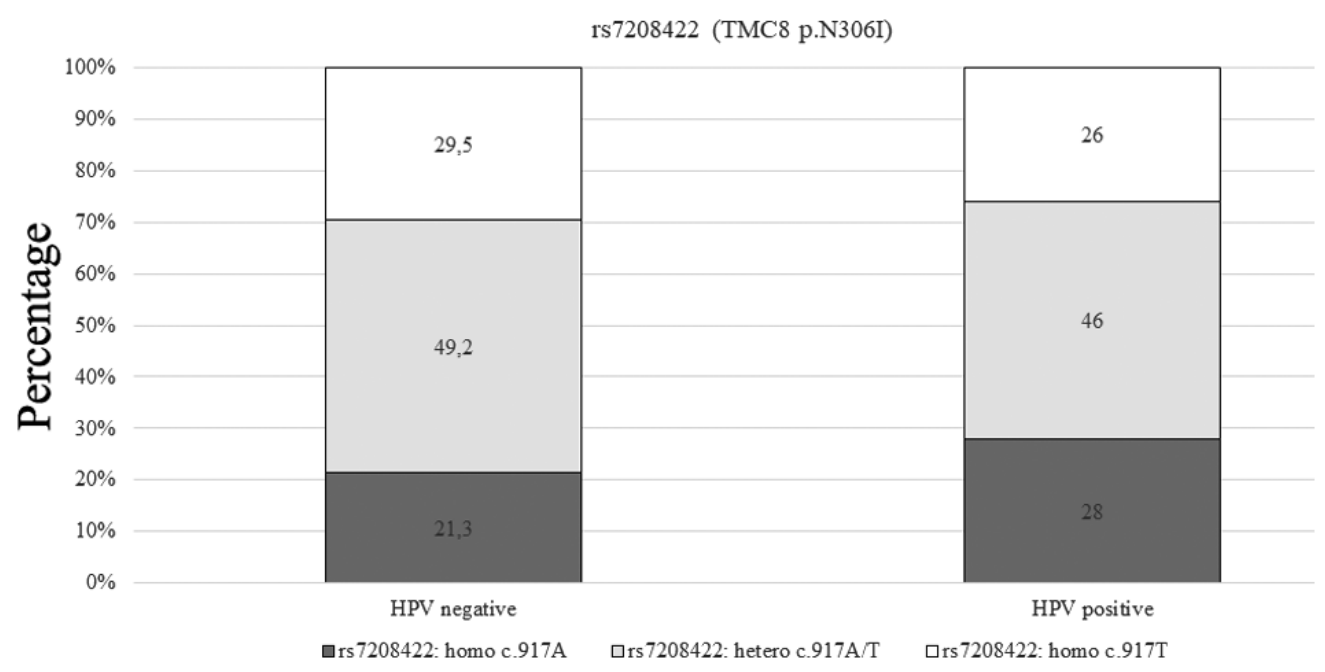

Figure 2. Distribution of rs7208422 genotypes compared between HPV-negative and HPV-positive penile carcinoma cases. HPV, human papillomavirus; homo, homozygous; hetero, heterozygous.

\section{Discussion}

The present study provided the first analysis of a potentially inherited susceptibility factor for HPV-dependent diseases in patients with penile SCC. The results suggested that the individual genotype status of rs7208422 did not influence the risk of penile SCC development in a Caucasian patient cohort.

One reason for the lack of an association between disease risk and genotype distribution may be the composition of the control group. As it was not possible to analyse an own control group of healthy individuals, combined literature data of both genders were used. This procedure included the possibility that the genotype distribution of rs7208422 differs between male and female individuals and that therefore, the statistical analysis was biased. To clarify this question, the genotype distribution between male and female individuals $(n=503)$ was analysed using data from the 1000 Genomes project (http://grch37.ensembl.org/Homo sapiens/Variation/Population? $\mathrm{r}=17: 76130075-7613$ 075; $\mathrm{v}=\mathrm{rs} 7$ 208422; vdb=variation;vf=128771294) (31) and there were no statistically significant differences in the allelic distribution between both sexes (data not shown). Furthermore, the allele frequencies of rs7208422 of the control cohort used for the present study matched the reported allele frequencies for the European population of the 1000 Genomes project, suggesting that the combined analysis of literature data did not bias the present analysis. In order to work with a conclusive number of controls to obtain the most comprehensive result, the data from the 1000 Genomes project were not used for the present analysis but all published literature data available were combined.

It is challenging to interpret the present results broadly, as no other study investigating the role of rs7208422 in penile SCC has been performed to date. The present results are in line with previous case-control studies on SCC of the cervix and of the head and neck, which are both $\alpha$-HPV-related tumor entities $(9,10)$. Contrary to these and the present findings, Liang et al (11) reported a significant association between genotype distribution of rs7208422 and seropositivity for HPV16 and -18, as well as a protective effect of the variant T allele in the presence of an infection with other HPV types in SCC of the head and neck. It was also attempted to analyse this possible association with the HPV subtype in the present study, but due to the low number of HPV16/18 $(n=21)$ and HPV13/31/33/45/52/58-positive cases $(n=5)$, no valid statistical analysis was possible. One reason for the contrary findings 
Table IV. Genotype distribution of rs7208422 in penile carcinoma cases according to median age at disease onset.

\begin{tabular}{lcc}
\hline Variant & Patients aged $\leq 68$ years $(\mathrm{n}=55)$ & Patents aged $>68$ years $(\mathrm{n}=49)$ \\
\hline TMC8 p.N306 & $14(25.4)$ & $11(22.5)$ \\
TMC8 p.N306/I306 & $25(45.5)$ & $25(51.0)$ \\
TMC8 p.I306 & $16(29.1)$ & $13(26.5)$
\end{tabular}

Values are expressed as n (\%). TMC, transmembrane channel-like.

Table V. Genotype distribution of rs7208422 in HPV-negative and HPV-positive penile carcinoma cases according to the dominant and recessive distribution models.

A, Dominant model

\begin{tabular}{lcc}
\hline Variants & HPV-negative $(\mathrm{n}=61)$ & HPV-positive $(\mathrm{n}=39)$ \\
\hline TMC8 p.N306 & $13(21.3)$ & $11(28.2)$ \\
TMC8 p.N306/I306 + p.I306 & $48(78.7)$ & $28(71.8)$ \\
\hline
\end{tabular}

B, Recessive model

\begin{tabular}{lccc}
\hline Variants & HPV-negative $(\mathrm{n}=61)$ & HPV-positive $(\mathrm{n}=39)$ & $\mathrm{P}$-value \\
\hline TMC8 p.I306 + p.N306/I306 & $43(70.5)$ & $29(74.4)$ \\
TMC8 p.I306 & $18(29.5)$ & $10(25.6)$
\end{tabular}

HPV, human papillomavirus; TMC, transmembrane channel-like.

may be the selection of the cases from only a tightly limited region (Greater Boston, MA,) and the focus on a small and heterogeneous ethnic group in the study from Liang et al (11).

Another point worth discussing regarding the possible role of rs7208422 in $\alpha$-HPV-related SCC is the expression of the viral E5/E8 proteins. The E5/8 proteins are short transmembrane proteins encoded by a wide range of papillomaviruses. Several functions have been described for this viral protein e.g. cell transformation activity, influence on the cell cycle and growth factors, induction of apoptosis and endoplasmic reticulum stress, as well as immune evasion (32). E5/E8 proteins target the cellular EVER/CIB1 complex to inhibit the zinc regulatory function of EVER proteins $(5,33)$. It has been suggested that the EVER/CIB1 complex acts directly as an anti-HPV barrier (13) that is actively disrupted by the viral protein. The amino acid change from isoleucine (non-polar) to asparagine (polar) may change the conformation of the transmembrane region of TCM8/EVER2 (34), but a potential influence of this change in the E5/E8-EVER/CIB1 interaction remains to be proven. However, HPV E5 protein was demonstrated to interact with numerous other cellular host proteins (e.g. EGFR, ErbB4) (35), so it is not clear whether a predisposition effect is to be expected alone from an influence of rs7208422 on E5/E8-EVER/CIB1 binding.

The most striking evidence for an involvement of rs7208422 in HPV-dependent disease predisposition was provided for $\beta$-HPV-related disorders such as actinic keratosis (AK), EV and its progression to non-melanoma skin cancer $(12,13,36)$. It was revealed that $\beta$-HPVs, which lack the E5 and E8 protein information, are not able to eliminate the EVER/CIB1 complex and are therefore unable to cause disease (33). Only in individuals exhibiting alterations (mutations, polymorphisms) within the EVER genes $(6,7)$, the absence/mutational disruption of this barrier complex enables the development of $\beta$-HPV-driven lesions. Of note, the development of EV is also possible without EVER gene alterations (37), indicating a more complex combination of various factors in the initiation of EV and $\beta$-HPV-related anomalies.

Another noteworthy point is the possible influence of genomic alterations at the chromosomal regions containing the EVER genes on $\beta$-HPV-related lesions. EVER1 and EVER2 are both located at chromosome 17q25. In previous studies on AK and SCC of the skin, loss of heterozygosity at chromosome $17 \mathrm{q}$ was detected in $>30 \%$ of cases analysed, whereas high-resolution array comparative genomic hybridization analyses revealed frequent loss of large areas of chromosome 17 (17p13.3-17q25.3) in up to $47 \%$ of SCC cases analysed $(38,39)$. In SCC of the penis, gains or losses of chromosome 17 have not been identified in both HPV-positive and HPV-negative cases, also arguing against any important role of the EVER gene locus in penile tumorigenesis (40).

Summing up all of these available data from the literature and the present study, it may be concluded that the TCM8/EVER2 SNP rs7208422 has no important role in 
disease risk and development of neither HPV-dependent nor HPV-independent SCC of the penis in Caucasian individuals. The combined data are in favor of a more critical role of rs720844 in the development of $\beta$-HPV-dependent diseases rather than $\alpha$-HPV-dependent diseases such as penile SCC.

Expanded analyses of additional SNPs already described to influence both the risk for other $\alpha$-HPV-related diseases (e.g. rs1801157) (40), as well as the general risk for developing a malignancy, should help to identify individuals with a high risk for the development of penile SCC in the future.

\section{Acknowledgements}

The authors thank Mrs. Verena Popp, Ms. Nina Oks, Mrs. Claudia Schmied, Ms. Daniela Renner, Ms. Petra Badorf and Mrs. Elisabeth Fantisch (all from the Institute of Pathology, University Hospital Erlangen, Erlangen, Germany) for their excellent technical assistance. Parts of this study were presented at the virtual 104th annual meeting of the German Association of Pathology from June 8-12, 2020.

\section{Funding}

No funding was received.

\section{Availability of data and materials}

The datasets used and/or analyzed during the current study are available from the corresponding author upon reasonable request.

\section{Authors' contributions}

Conceptualization, RS and $\mathrm{AH}$; methodology, RS and OW; investigation, RS, OW, JG, NTG; analysis of data, GR, $\mathrm{VC}, \mathrm{MB}, \mathrm{BW}, \mathrm{SB}$; writing-original draft preparation, RS; writing-review and editing, AH, OW, JG, NTG, GR, VC, MB, BW, SB; supervision, RS, AH. All authors have read and agreed to the published version of the manuscript. RS and $\mathrm{AH}$ checked and approved the authenticity of the raw data.

\section{Ethics approval and consent to participate}

Prior institutional review board approval (University Hospital Erlangen, Erlangen, Germany) was obtained for the scientific use of archival tissue material (reference no. 3755).

\section{Patient consent for publication}

Not applicable.

\section{Competing interests}

The authors declare that they have no competing interests.

\section{References}

1. Brianti P, De Flammineis E and Mercuri SR: Review of HPV-related diseases and cancers. New Microbiol 40: 80-85, 2017.

2. Gupta S, Kumar P and Das BC: HPV: Molecular pathways and targets. Curr Probl Cancer 42: 161-174, 2018.
3. Oyervides-MuñozMA,Pérez-Maya AA,Rodríguez-GutiérrezHF, Gómez-Macias GS, Fajardo-Ramírez OR, Treviño V, Barrera-Saldaña HA and Garza-Rodríguez ML: Understanding the HPV integration and its progression to cervical cancer. Infect Genet Evol 61: 134-144, 2018.

4. Kalińska-Bienias A, Kowalewski C and Majewski S: The EVER genes-the genetic etiology of carcinogenesis in epidermodysplasia verruciformis and a possible role in non-epidermodysplasia verruciformis patients. Postepy Dermatol Alergol 33: 75-80, 2016.

5. Lazarczyk M, Pons C, Mendoza JA, Cassonnet P, Jacob Y and Favre M: Regulation of cellular zinc balance as a potential mechanism of EVER-mediated protection against pathogenesis by cutaneous oncogenic human papillomaviruses. J Exp Med 205: 35-42, 2008.

6. Arnold AW, Burger B, Kump E, Rufle A, Tyring SK, Kempf W, Häusermann P and Itin PH: Homozygosity for the c.917A $\rightarrow$ T (p.N3061) polymorphism in the EVER2/TMC8 gene of two sisters with epidermodysplasia verruciformis Lewandowsky-Lutz originally described by Wilhelm Lutz. Dermatology 222: 81-86, 2011.

7. Hohenstein E, Rady PL, Hergersberg M, Huber AR, Tyring SK, Bregenzer T, Streit M and Itin P: Epidermodysplasia verruciformis in a HIV-positive patient homozygous for the c917A $\rightarrow \mathrm{T}$ polymorphism in the TMC8/EVER2 gene. Dermatology 218: 114-118, 2009.

8. Zuo YG, Ma D, Zhang Y, Qiao J and Wang B: Identification of a novel mutation and a genetic polymorphism of EVER1 gene in two families with epidermodysplasia verruciformis. J Dermatol Sci 44: 153-159, 2006

9. Castro FA, Ivansson EL, Schmitt M, Juko-Pecirep I, Kjellberg L, Hildesheim A, Gyllensten UB and Pawlita M: Contribution of TMC6 and TMC8 (EVER1 and EVER2) variants to cervical cancer susceptibility. Int J Cancer 130: 349-355, 2012.

10. Antonsson A, Law MH, Neale RE, Coman WB, Pryor DI; Study of Digestive Health (SDH), Porceddu SV and Whiteman DC: Variants of EVER1 and EVER2 (TMC6 and TMC8) and human papillomavirus status in patients with mucosal squamous cell carcinoma of the head and neck. Cancer Causes Control 27: 809-815, 2016.

11. Liang C, Kelsey KT, McClean MD, Christensen BC, Marsit CJ, Karagas MR, Waterboer T, Pawlita $\mathrm{M}$ and Nelson $\mathrm{HH}$ : A coding variant in TMC8 (EVER2) is associated with high risk HPV infection and head and neck cancer risk. PLoS One 10: e0123716, 2015.

12. Patel AS, Karagas MR, Pawlita M, Waterboer T and Nelson HH: Cutaneous human papillomavirus infection, the EVER2 gene and incidence of squamous cell carcinoma: A case-control study. Int J Cancer 122: 2377-2379, 2008

13. Hampras SS, Rollison DE, Tommasino M, Gheit T, Schabath MB, Messina JL, Fenske NA, Cherpelis BS, Sondak VK, Iannacone MR, et al: Genetic variations in the epidermodysplasia verruciformis (EVER/TMC) genes, cutaneous human papillomavirus infection and squamous cell carcinoma of the skin. Br J Dermatol 173: 1532-1535, 2015.

14. Pavlidou E, Daponte A, Egea R, Dardiotis E, Hadjigeorgiou GM, Barbadilla A and Agorastos T: Genetic polymorphisms of FAS and EVER genes in a Greek population and their susceptibility to cervical cancer: A case control study. BMC Cancer 16: 923 , 2016.

15. Wang SS, Gonzalez P, Yu K, Porras C, Li Q, Safaeian M, Rodriguez AC, Sherman ME, Bratti C, Schiffman M, et al: Common genetic variants and risk for HPV persistence and progression to cervical cancer. PLoS One 5: e8667, 2010.

16. Iorga L, Dragos Marcu R, Cristina Diaconu C, Maria Alexandra Stanescu A, Pantea Stoian A, Liviu Dorel Mischianu D, Surcel M, Bungau S, Constantin T, Boda D, et al: Penile carcinoma and HPV infection (review). Exp Ther Med 20: 91-96, 2020.

17. Srinivas V, Morse MJ, Herr HW, Sogani PC and Whitmore WF Jr: Penile cancer: Relation of extent of nodal metastasis to survival. J Urol 137: 880-882, 1987.

18. Hakenberg OW, Compérat EM, Minhas S, Necchi A, Protzel C and Watkin N: EAU guidelines on penile cancer: 2014 update. Eur Urol 67: 142-150, 2015.

19. Kroon BK, Horenblas S and Nieweg OE: Contemporary management of penile squamous cell carcinoma. J Surg Oncol 89: 43-50, 2005.

20. Alemany L, Cubilla A, Halec G, Kasamatsu E, Quirós B, Masferrer E, Tous S, Lloveras B, Hernández-Suarez G, Lonsdale R, et al: Role of human papillomavirus in penile carcinomas worldwide. Eur Urol 69: 953-961, 2016. 
21. Emmanuel A, Nettleton J, Watkin N and Berney DM: The molecular pathogenesis of penile carcinoma-current developments and understanding. Virchows Arch 475: 397-405, 2019.

22. Moch H, Cubilla AL, Humphrey PA, Reuter VE and Ulbright TM: The 2016 WHO classification of tumours of the urinary system and male genital organs-part A: Renal, penile, and testicular tumours. Eur Urol 70: 93-105, 2016.

23. Brierley JD, Gospodarowicz MK and Wittekind C (eds): TNM classification of malignant tumours. 8th edition. Wiley Blackwell, United Kingdom, 2017.

24. Stoehr R, Weisser R, Wendler O, Giedl J, Daifalla K, Gaisa NT, Richter G, Campean V, Burger M, Wullich B and Hartmann A: P53 codon 72 polymorphism and risk for squamous cell carcinoma of the penis: A caucasian case-control study. J Cancer 9: 4234-4241, 2018.

25. Weyerer V, Schneckenpointner R, Filbeck T, Burger M, Hofstaedter F, Wild PJ, Fine SW, Humphrey PA, Dehner LP, Amin MB, et al: Immunohistochemical and molecular characterizations in urothelial carcinoma of bladder in patients less than 45 years. J Cancer 8: 323-331, 2017.

26. de Roda Husman AM, Walboomers JM, van den Brule AJ, Meijer CJ and Snijders PJ: The use of general primers GP5 and GP6 elongated at their 3'ends with adjacent highly conserved sequences improves human papillomavirus detection by PCR J Gen Virol 76: 1057-1062, 1995.

27. Lin CY, Chao A, Yang YC, Chou HH, Ho CM, Lin RW, Chang TC, Chiou JY, Chao FY, Wang KL, et al: Human papillomavirus typing with a polymerase chain reaction-based genotyping array compared with type-specific PCR. J Clin Virol 42: 361-367, 2008

28. Sahiner F, Kubar A, Yapar M, Şener K, Dede M and Gümral R: Detection of major HPVs by a new multiplex real-time PCR assay using type-specific primers. J Microbiol Methods 97 44-50, 2014.

29. Kalinska-Bienias A, Kowalewski C, Kostrzewa G, Malejczyk M, Ploski R and Majewski S: Possible association between actinic keratosis and polymorphism rs7208422 (c.917A $\rightarrow$ T, p.N3061) of EVER2 gene in non-epidermodysplasia verruciformis patients J Invest Dermatol 134: S22, 2014

30. Burger B, Spörri I, Stegmann DA, De Mesmaker J, Schaub S, Itin PH, Steiger J and Arnold AW: Risk of cutaneous squamous cell carcinoma development in renal transplant recipients is independent of TMC/EVER alterations. Dermatology 231: 245-252, 2015.
31. Kent WJ, Sugnet CW, Furey TS, Roskin KM, Pringle TH, Zahler AM and Haussler D: The human genome browser at UCSC. Genome Res 12: 996-1006, 2002.

32. Hemmat $\mathrm{N}$ and Baghi HB: Human papillomavirus $\mathrm{E} 5$ protein, the undercover culprit of tumorigenesis. Infect Agent Cancer 13: 31, 2018.

33. de Jong SJ, Crequer A, Matos I, Hum D, Gunasekharan V, Lorenzo L, Jabot-Hanin F, Imahorn E, Arias A A, Vahidnezhad H, et al: The human CIB1-EVER1-EVER2 complex governs keratinocyte-intrinsic immunity to $\beta$-papillomaviruses. J Exp Med 215: 2289-2310, 2018.

34. Lazarczyk M, Cassonnet P, Pons C, Jacob Y and Favre M: The EVER proteins as a natural barrier against papillomaviruses: A new insight into the pathogenesis of human papillomavirus infections. Microbiol Mol Biol Rev 73: 348-370, 2009.

35. Scarth JA, Patterson MR, Morgan EL and Macdonald A: The human papillomavirus oncoproteins: A review of the host pathways targeted on the road to transformation. J Gen Virol 102: 001540, 2021

36. Kalinska-Bienias A, Kostrzewa G, Malejczyk M, Ploski R and Majewski S: Possible association between actinic keratosis and the rs7208422 (c.917A $\rightarrow$ T, p.N3061) polymorphism of the EVER2 gene in patients without epidermodysplasia verruciformis. Clin Exp Dermatol 40: 318-323, 2015.

37. McDermott DF, Gammon B, Snijders PJ, Mbata I, Phifer B, Howland Hartley A, Lee CC, Murphy PM and Hwang ST: Autosomal dominant epidermodysplasia verruciformis lacking a known EVER1 or EVER2 mutation. Pediatr Dermatol 26: 306-310, 2009.

38. Quinn AG, Sikkink S and Rees JL: Basal cell carcinomas and squamous cell carcinomas of human skin show distinct patterns of chromosome loss. Cancer Res 54: 4756-4759, 1994.

39. Li J, Wang K, Gao F, Jensen TD, Li ST, DeAngelis PM, Kølvraa S, Proby C, Forslund O, Bolund L and Clausen OP: Array comparative genomic hybridization of keratoacanthomas and squamous cell carcinomas: Different patterns of genetic aberrations suggest two distinct entities. J Invest Dermatol 132: 2060-2066, 2012.

40. Busso-Lopes AF, Marchi FA, Kuasne H, Scapulatempo-Neto C, Trindade-Filho JC, de Jesus CM, Lopes A, Guimarães GC and Rogatto SR: Genomic profiling of human penile carcinoma predicts worse prognosis and survival. Cancer Prev Res (Phila) 8: 149-156, 2015. 